\title{
A Proposed Module for the Course Modalities and Assessment of Learning in Post-Baccalaureate Diploma in Alternative Learning System (PB-DALS)
}

\author{
Rufo A. Labarrete
}

\section{ABSTRACT}

\begin{abstract}
This study proposed two modules for the course Modalities and Assessment for Learning in PB-DALS. The 4As strategy on teaching as suggested in Kolb's Experiential Learning Theory served as its core design. As such, it follows the Activity, Analysis, Abstraction, and Application phases of lesson episodes. Its contents, on the other hand, are reflective on the results of the findings reported as regards modalities and assessments of learning employed by the ALS programs implementers across diverse groups. These modules are deemed useful for teachers of PB-DALS, ALS programs implementers, and policy makers of the ALS. Taking things holistically, it is suggested that said modules be subjected for validation.
\end{abstract}

Keywords: Assessment for Learning, Learning Module, Modalities for Learning, Post-Baccalaureate Diploma in Alternative Learning System, Modules in PB-DALS.

\section{INTRODUCTION}

The recent institutionalization of RA 10533 or the Enhanced Basic Education Act of 2013 paved the way for another round of reforms in the Philippines basic education sector. Specifically, for the ALS, the DepEd issued DO 013 s. 2019 [1] or the Policy Guidelines on the Implementation of Enhanced Alternative Learning System 2.0 or ALS 2.0. In the same order, ALS 2.0 is explained as an enhanced, strengthened, and expanded ALS of the country. This reform implemented in the basic education sector had spiraled up to the country's Higher Education Institutions (HEIs). As DepEd's manpower service provider, the Commission on Higher Education (CHED) enjoined HEIs, both state-run and private, to consider offering Post-Baccalaureate Diploma in Alternative Learning System (PB-DALS). As explained in CMO 83, s. 2017, [2] PB-DALS is a diploma program commensurate to 30 -unit courses. These courses are carefully chosen to provide ALS would-be practitioners appropriate tertiary education training, thereby, equip them with knowledge and skills direly needed in the practice of the profession in the field. Since this diploma program is novel, concerns like those on instructional resources is inevitable. This academic undertaking then is pivoted to developing a module for the course Modalities and Assessment of Learning in PB-DALS.

\author{
Published Online: June 23, 2021 \\ ISSN: $2736-4534$ \\ DOI :10.24018/ejedu.2021.2.3.42 \\ Rufo A. Labarrete, $\mathrm{PhD}$ \\ Leyte Normal University, Tacloban City, \\ Leyte, the Philippines. \\ (e-mail: labarrete@yahoo.com) \\ *Corresponding Author
}

\section{METHODS}

\section{A. Phase One}

Modalities and Assessment of Learning in the ALS is a 3unit course of the PB-DALS. In CMO 83 s. 2017, it is explained that the ALS utilizes various modalities and formats for learning under coexisting measures. These assessment formats are designed to evaluate learning primarily on fundamental and functional literacy in elementary and secondary levels. As such, the course intends to enable learners to help them arrived at informed enable learners to help them arrived at informed choices as regards to modalities and assessment formats considering the learners' interests, needs, and experience or prior learning, as well as on the availability of resources in the community.

In the development of the proposed module, the researcher identified the modalities for learning as well as the formats for assessing learning employed by the program's implementers in the ALS. In a study the researcher published, Labarrete [3] it was reported that the modalities employed by the ALS programs implementers in teaching the learners classified as Persons Deprived of Liberty (PDLs), Indigenous People, and Non-Literate Adults is the face-to-face instructional modality. It is aided by the use of radio and modern and traditional technologies. Home visitation is also conducted. Overall, the researcher claimed, it can be categorical to claim that the manner by which instruction is delivered in the ALS is responsive in addressing learners' 
various needs given their circumstances.

As regards, formats on assessment for learning, Labarrete [4] reported in a case study he conducted that there are three basic formats utilized in the Alternative Learning SystemEducation Skills Training (ALS-EST) in assessing for students learning. These are the portfolio-based, modulebased, and performance-based assessments. The use of these assessment formats, the author claimed, strongly suggests the fact that assessment is carried out in a multidimensional manner. This, he said, implies then that learners' diversity is addressed. Additionally, this practice also suggests that differentiation which is achieved through the adherence of multiple assessment formats is observed specifically on assessment. Given these, it can be said that these practices are in consonance with what is called for in the current implementation of the ALS 2.0 curriculum. The researcher acknowledged though that these assessment formats are meant for those in enrolled in the EST program, thus, the study's delimitation.

The results mentioned and discussed above served as the bases for the development of a proposed module for the course Modalities and Assessment of Learning in PB-DALS. Given this, the author proposed two modules for the course. Module One is titled as Modalities of Learning in the ALS while Module Two is Assessment in the ALS. Each module has corresponding number of lessons enough to provide the target learners or groups holistic information on modalities of learning and assessment of learning utilized in the field by the programs implementers. The modules are anchored on CMO 83 s. 2017 standards alignment and in accordance with Outcome Based Education (OBE) with its components including: Intended Learning Outcome, Content, Teaching and Learning Activities and Assessment Tasks. Additionally, it is likewise anchored on the SALAS model which serves as framework by which the granular learning theory generated in this study is operationalized.

The learning tasks included in all of its lessons are designed based on the 4As strategy on teaching as suggested in Kolb's Experiential Learning Theory. The 4As include: Activity - background knowledge activation; Analysis tasks processing; Abstraction - lesson presentation and discussion; and Application - translating theories to practice.

These course modules are intended for use by prospective ALS teachers enrolled in the course Modalities and Assessment of Learning in the ALS of the PB-DALS program offered by an institution for higher learning, the course Professor and by the ALS managers such as the District ALS Coordinators who wish to conduct seminar-orientation involving newly hired ALS teachers of the DepEd without background knowledge about the nuances inherent to the pedagogic practices in the ALS especially as regards to instructional delivery and assessment of learning given its diverse groups of learners.

\section{B. Module's Contents}

\section{Module One}

Lesson One: Scouting for Potential ALS Learners: The

School Going to Where the Learners Are.

Lesson Two: Assessing Recruited ALS Learners Lesson Three: Linking Assessment Results with the Learning Strands Lesson Four: Instructional Delivery in the ALS.

\section{Module Two}

Lesson One: Portfolio-Based Assessment in the ALS.

Lesson Two: Formative Assessment in the ALS.

Lesson Three: Module-Based Assessment in the ALS: Lesson Four: Performance-Based Assessment in the ALS; and Lesson Five: Sustaining Learning Momentum in the ALS Through Informal Education (InFed).

\section{RESULTS}

\section{A. Overview for Module One}

\section{Modalities of Learning in the Alternative Learning} System

Module one enables both the prospect ALS teachers and those in-service ALS teachers without orientation as regards to the pedagogic practices in this unique learning environment to take a broad endured by the field programs implementers relative to recruitment for potential learners

2. Sample Lesson for Module One

\section{Lesson One}

Scouting for Potential ALS Learners: The School Going to Where the Learners Are

\section{Intended Learning Outcomes}

At the end of the session, the learners are able to:

1) Write a script for a pep-talk to be able to convince potential learners who could be mainstreamed to the ALS. Include in it the many educational advantages that maybe gained for their attendance.

2) Interview successful ALS learners in the community.

3) Write a reflection paper about the value of ALS to its learners.

Key Terminologies

ALS Behind Bars - an ALS program intended for the Persons Deprived of Liberty (PDLs) or those serving prison terms.

Indigenous Peoples Education (IPEd) - an ALS programs intended for the IPs living in a specific community.

Pep-Talk - refers to the strategy of talking to a group of individuals to convince them to say buy a product or attend assemblies.

Survey - in this lesson, this refers to the strategy use by the ALS programs implementers to look for learners in the community who could be candidates for enrollment in the ALS.

\section{Teaching and Learning Activities}

Activity

Teachers' Task: Present this photo to the class. Ask the learners to write all their thoughts and ideas about the photo and let them write those on the bubbles.

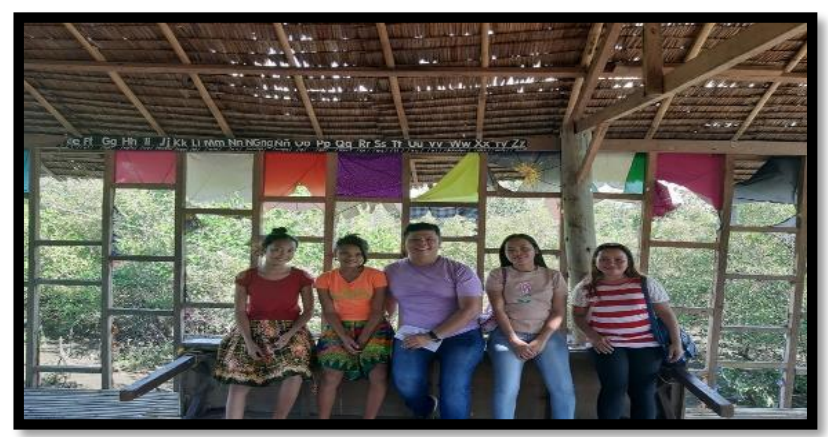

Photo Credit to: ALS-IP Implementers in Isabel, Leyte, Philippines. 


\section{Learners' Task}

A. Write your thoughts on the picture presented to you by your teacher. Include only the BIG WORDS that will encapsulate your idea. You may add more bubbles to accommodate more ideas.

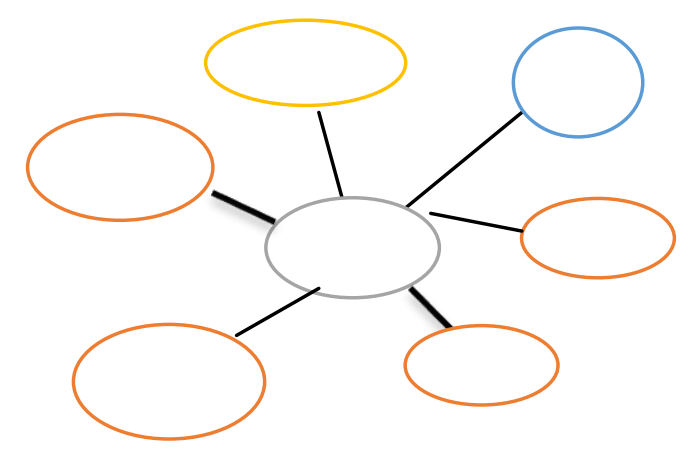

B. Can I have your thoughts on this?

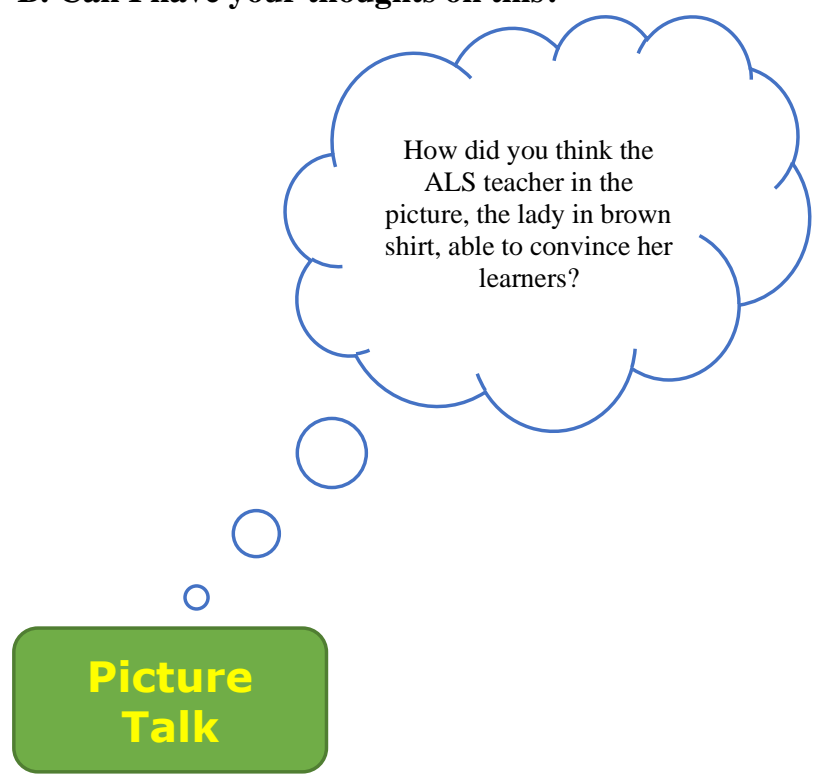

Analysis

Teachers' Task: Given the learners' answers in Tasks A and B let them answer the questions below.

Learners' Task: Answer the following questions.

1. What type of learners do you think are seated with the implementers in the photo presented by your teacher?

Answer:

2. Where do you think does the teacher deliver her instruction?

Answer:

3. Given the nature of the learners that the ALS teacher has, how do you think did the teacher convince them to join the ALS and be part of its group of learners?

Answer:

4. What strategy do you think the teacher utilized to learn that such a group of learners exist in her own community? Answer:

\section{Abstraction}

Teachers' Task: Ask your learners to read the discussion below about how ALS field implementers search for possible learners within their assigned cluster of communities. Guide them as well as they go along with this task.

Learners' Task: Read the text below.

It is said that in the ALS, it's the school that goes to the learners. It follows therefore that conducting a community survey for potential learners who could be mainstreamed to the system is the first among the series of steps prior to programs implementation. Surveying is usually utilized by the programs implementers as mechanism to be able to scout and eventually recruit potential learners who may qualify for enrollment in one of the system's lists of programs offerings. The search for learners is usually conducted within the implementers pre-assigned communities clustered within a specific district learning center on a year round basis. Apart from the barangays and its sitios, if there are any, government facilities such as those intended for rehabilitation of juvenile delinquent youths both boys and girls, prison facilities where there is a presence of imminent learners who could potentially be mainstreamed to the system as well as the communities for the minority groups are also surveyed. This move intends to reach out all social groups in a bid to make education inclusive, and, in turn, provide chance to all those who for various circumstances were forced to leave or drop out from school. Subsequently, qualified learners are endorsed to the Division Office for listing to the Learners Information System (LIS). As an institutional policy, program implementers are required to recruit 75 learners or more per academic year.

In surveying for potential enrollees, the ALS Division Office through its ALS Supervisor and the programs implementers, usually enters into a Memorandum of Agreement (MOA) with the community stakeholders such as the barangay officials, head of different government agencies such as if there are facilities for rehabilitation under the care of DSWD, jail facilities controlled by either the Province, Bureau of Jail Management and Penology, or that of the Department of Justice.

The Division of Leyte, for example, has partnered with the prison facilities in the province such as the Leyte Regional Prison (LRP), Bureau of Jail Management and Penology (BJMP), DSWD controlled facilities specifically at the Regional Rehabilitation Center for Youths and Home for Girls in the towns of Tanauan and Palo respectively. Its program offering is called as ALS Behind Bars. Furthermore, the IP communities are also included in the survey. By now, the Leyte Division has ALS programs offerings to the SamaBadjaos in the towns of Bato and Isabel. This is in response to its program called IPEd.

As a matter of policy therefore, recruitment for potential learners in the ALS goes beyond those living in the barangays and sitios to include those housed in government facilities like penal colonies located within the area under the care of the programs implementers in a specific ALS District of a town. Following this, recruited learners are assigned with a Learner Reference Number (LRN). LRN is a 12digit number assigned by the DepEd to each learner. This is usually use as a main reference for a specific student as he/she goes through the process of completing the basic education. It can be tracked on the top most of Form 138 or the Report Card. Finally, all recruited learners with LRN are reported to the Division for the piling at its Learners Information System 
(LIS).

\section{Application \\ Points for Discussions \\ Teachers' Tasks:}

1. Form a small group of 3-5 members in your class.

2. Require each group to conduct a pep-talk in the class.

3. Instruct them that somebody has to assume the role as programs implementers while the rest of the class members as potential ALS learners in the community.

4. Present to the class the rubrics by which they will have to be rated on both their oral and written outputs.

5. Ask the class to present their work as group and then let the entire class critique the group's presentation.

6 . Rate the group work based on the given rubrics.

\section{Learners' Tasks:}

1. In this segment of the lesson, you will conduct a peptalk to a particular group of ALS learners, for this purpose, some of your classmates' will assume the role as ALS learners. Make sure that the pep-talk include the many educational gains one may enjoy from attending the ALS. However, before you do that, along with your groupmates, write a script for your pep-talk first.

2. Present your pep-talk to the class. To gain high score, be mindful of the rubrics presented to you by your teacher.

3. Be ready for class critiquing to further solicit ideas and eventually write a revised or modified version of your original script.

\section{Group's Script.}

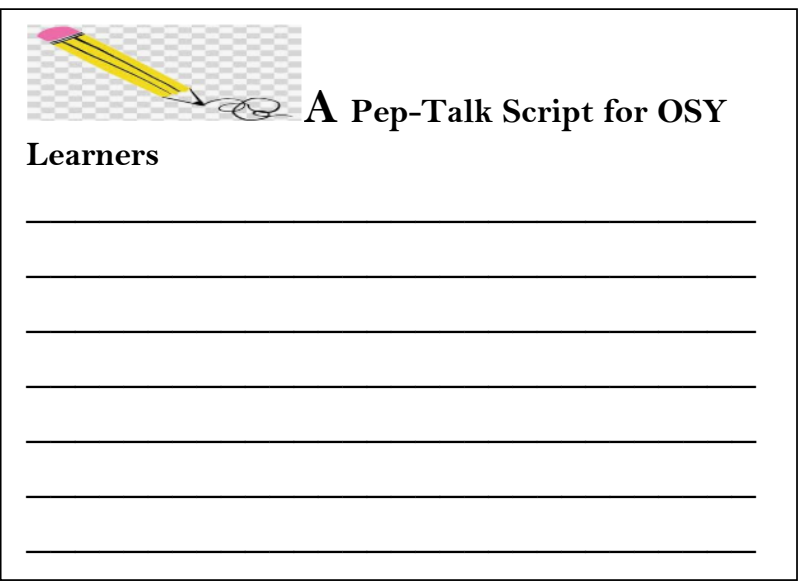

2. Class Oral Presentation and Critiquing of the Pep-Talk Presented.

3. Feedbacking.

\section{Assessment Task}

Teachers' Task: Instruct the learners to perform the tasks below and rate their written output using the rubric for written outputs.

Learners' Task: Perform the following activities. Interview successful ALS programs completers in your respective barangay. Record (video or tape) the activity. Then, write a reflection paper about the true meaning of the ALS to people who were unfortunate not to have entered the school grounds and / or terminated their studies earlier than the required time frame for the completion of a grade level.

$\checkmark$ My Reflection Paper

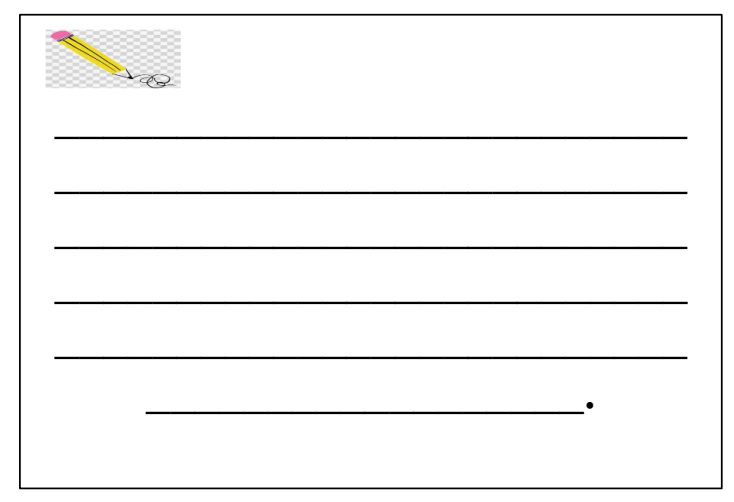

\section{Sample Lesson for Module One}

\section{B. Overview for Module Two}

Assessment of Learning in the Alternative Learning System

Module two is focused on assessment of learning in the ALS. Unarguably, assessment play a pivotal role in the entire teaching and learning episodes. In the ALS, programs implementers are tasked as well to assess students' learning. This episode, the assessment, is part of the actualization of the instruction. There are four assessment formats that are commonly used in the ALS. These include the portfolio, module, performance, and formative assessments. Each format is uniquely implemented and link to a specific purpose depending on the group of learners being assessed. To ensure a comprehensive discussion for each of the format, it was decided then that each be assigned a lesson. So that, lessons one to four are devoted for assessment making it occupies a significant space in the module's content. The final lesson included in this module, talks about sustaining learning momentum, the last dimension of the SALAS model which operationalizes the granular learning theory generated in this study.

\section{Sample Lesson for Module One}

Lesson Five: Sustaining Learning Momentum in the ALS Through Informal Education (InFed)

\section{Intended Learning Outcomes:}

At the end of the session, the learners are able to:

1. Design a rubric for a specific activity in Informal Education (InFed).

2. Write a learning plan based on the narratives of the field ALS programs implementers as regards to their best practices relative to the implementation of InFed.

\section{Key Terminologies}

Informal Education - refers to the learning processes that are acquired outside the formal trainings provided by the programs implementers in the ALS.

Life skills - is considered as component skills in the ALS that refers to self-development to augment once knowledge, skills, and attitudes.

\section{Teaching and Learning Activities Activity}

Teachers' Task: Let the learners perform the task below. Learners' Task: Read the news article below and answer the questions that follow.

Xavier Ateneo Night School Program hosts CDO-ALS 
inter-district Sports fest.

Text and photos by Jett Torres.

https://www.xu.edu.ph/xavier-news/140-2018-

2019/3744-xavier-ateneo-night-school-program-hosts-

cdo-als-internet-district-sports-fest.

Xavier Ateneo Night School Program fosters a culture of diverse learning methods to reach the highest level of achievement among its learners. The program is committed to empowering the various talents and skills of the youth through sports and wellness activities. The Night School Program, one of the Department of Education's Alternative Learning System (DepEd-ALS) centers in Cagayan de Oro City, hosted the annual invitational sports fest and Larong Pinoy with the theme "Dula Ta ALS" on October 7, 20, and November 4, 2018, at the XU covered courts, in partnership with the University Athletics office, University Varsity team, and Arrupe Educational Center volunteers. The activity was participated by 11 teams from different districts in the city, namely, Central District, East I \& II Districts, North I \& II Districts, South District, South West District I \& II, West I \& II Districts, and XU Night School Program. The activity allowed the learners to develop their psychomotor skills through active movement, speed, and healthy outlet for energy boosting. It promoted camaraderie among the learners, mobile teachers, coordinator, and student-volunteers that enabled them to build healthy relationships within their own districts.

DepEd - Region X ALS coordinator Dr. Ray Butch Mahinay appreciated the sportsmanship and healthy competition among ALS learners. For him, the sports fest has created unity and improved the morale of the learners. The basketball championship was won by the West I district and South district won in volleyball championship game. XU Night School Program was declared as the overall champion in the Larong Pinoy. The Night School Program continues to nurture responsible and productive learners that will constantly embrace change, capable to define oneself and to become leaders in their own community in collaboration with CDO DepEd-ALS.

\section{Guide Questions:}

1. Why was the sports fest launched?

Answer:

2. What were the ultimate purposes of launching the sports fest?

Answer:

3. What have the ALS learners gained from participating in the sports fest?

Answer:

\section{Analysis}

Teachers' Task: Facilitate the instructional phase of this module.

Learners' Task: Examine closely the pictures below and answer the questions that follow.
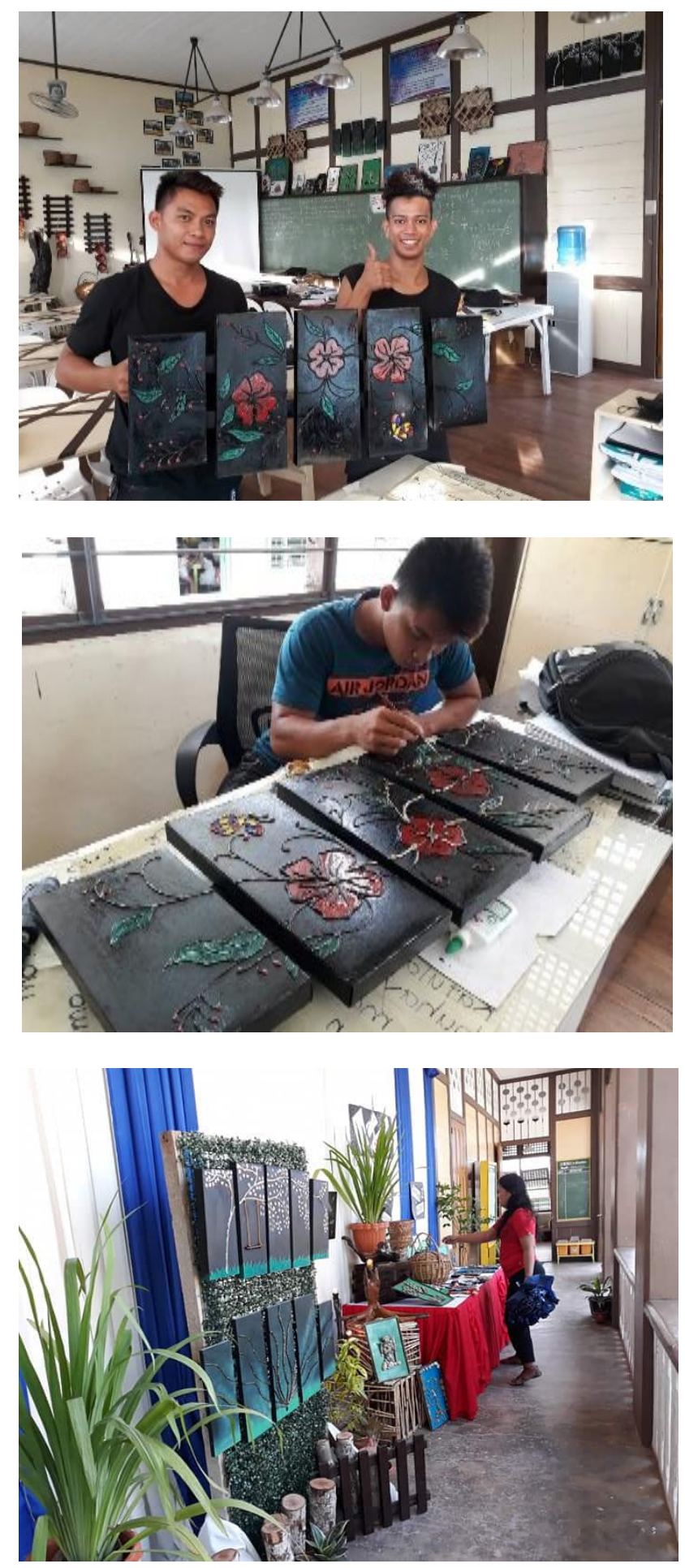

Photo Credit to: Valeriano, Ronald, ALS Master Teacher, San Miguel, Leyte, Philippines.

1. Why do you think are ALS learners encouraged to do the tasks such as what are depicted in the pictures?

\section{Answer:}

2. What do you think are the value or importance of these types of activities?

Answer:

3. Are you in favor of these kinds of activities in school? Why?

Answer:

4. Given the news article that you have read earlier and the above, what ideas do you have about informal education?

Answer: 


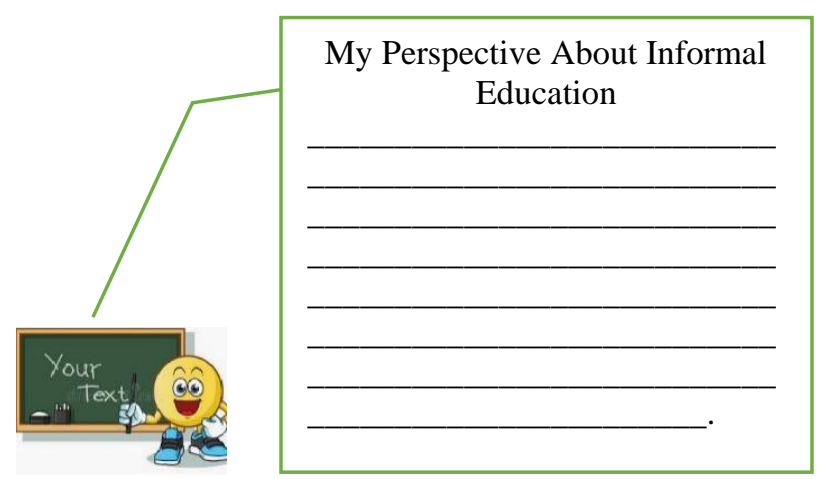

Abstraction

Teachers' Task: Let the learners perform the task below. Learners' Task: Ask your learners to read the discussion below about InFed.

\section{Informal Education in the ALS}

Informal Education is a component of the ALS that complements the non-formal education. It aims to create opportunities for self-development in accordance to the learners' interest paving the way towards a timely and relevant acquisition of skills. Additionally, this is also considered as life-wide and life-long education. These means that there are many skills that are deemed irrelevant at certain point of our lives but resurfaced to be highly needed at present time. Similarly, people expand also their areas of interests as well as change their priorities in life, and, in turn, change their needs for learning. This is where InFed comes into the picture. In the ALS, InFed is delivered through a learning facilitator who plays the role of a coach or role model skilled enough to be able to influence or transfer the same to his or her learners. There are three fundamental roles of the ALS implementers for facilitating InFed. First, identifying learners' needs. For this role, ALS programs implementers are expected to gather information on the whereabouts of his or her learners through the conduct of interviews, observations, and be able to look what is termed in the ALS as "environmental triggers" such as social issues, health warnings, among others that can ultimately generate learning needs. Second, finding training providers. ALS programs implementers are expected to tie-up with the industries in their respective communities and ensure matching of the learners' skills and needs. Finally, the third role is managing the InFed program. This role means that ALS programs implementers are expected to be able to organize and manage the InFed programs by addressing its immediate concerns and needs especially those relating to logistics Cañete [5].

In Leyte Division, specifically for the EST, IPs, PDLs, and Non-Literate Adults, InFed is materialized through the conduct of various extra-curricular activities such as the Sports Festival, skills trainings, products developments that usually benefits the learners. Activities like for the former are Tree Planting, ROVERS Scouting or the college type scouting, handicraft making, mock job interviews, among others are some conducted for InFed.

\footnotetext{
Application

Teachers' Task: Let the learners to perform the tasks below.
}

Learners' Task: Design a rubric for the following activities in the InFed.

\section{Table Setting}

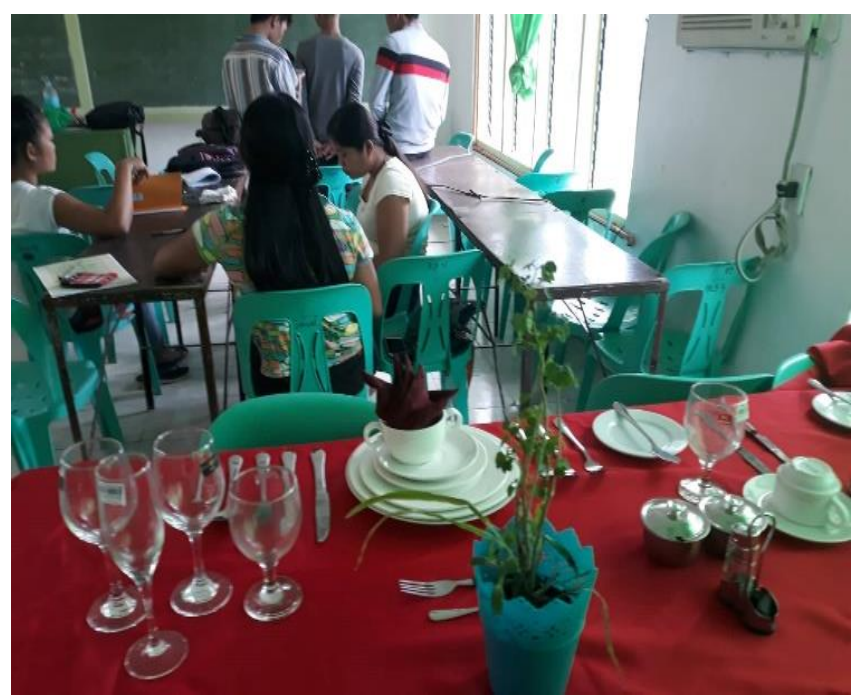

\section{Handicraft Making}

Mock Job Interview

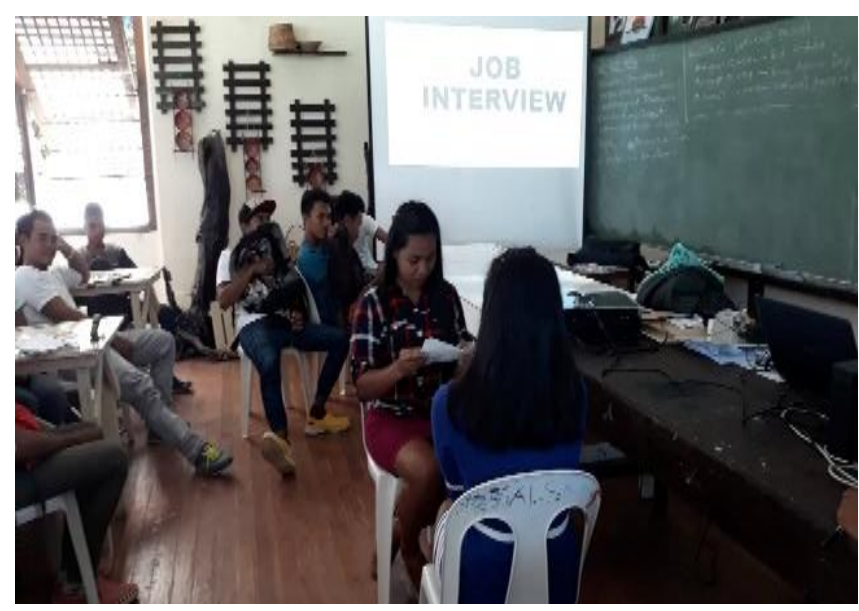

Photo Credit to: Valeriano, Ronald, Master Teacher, ALS San Miguel, Leyte, Philippines

\section{Assessment Tasks}

Teachers' Task: Let the learners perform the tasks below.

Learners' Task: Conduct an interview involving the ALS programs implementers for the EST, IPs, Non-Literate Adults, and PDLs. Ask them about their best practices the implementation of InFed for each of group. Then, select one activity you like the most as discussed by the select interviewees. Afterwards, design a rubric for the said activity.

\section{DISCUSSIONS}

This study intends to propose a module for the course Modalities and Assessment in Learning in ALS in PB-DALS. The proposed module is designed based on the 4As strategy on teaching as suggested in Kolb's Experiential Learning Theory. The 4As include Activity - background knowledge activation; Analysis-tasks processing; Abstraction-lesson presentation and discussion; and Application - translation 
theories to practice. Its lesson contents are based on the results of the studies conducted by the researcher himself pertinent to the modalities and assessment of learning in the ALS. The proposed module necessitates implementation and validation. Results of such will then serve as the bases to further improve the learning material. Additionally, it is recommended that further studies be conducted on assessment formats utilized in the ALS to include all other program offerings as the basis for the development of module two as the current module content are based on the results of the case study conducted by the researcher himself which only involves those assessment formats used in the ALS-EST.

\section{REFERENCES}

[1] DO 013, s. 2019 - deped.gov.ph. (July 2019.). Retrieved from:https://www.deped.gov.ph/wpcontent/uploads/2019/06/DO_s2019_013.pdf

[2] CMO 83, s. 2017- ched.gov.ph (July 2019). Retrievedfromhttps://ched.gov.ph/wp-content/uploads/2017/11/CMONo.-83s2017.pdf.

[3] Cañete, A. (2016). Elements of Alternative Learning System (ALS) Informal Education (InFed). Retrieved from teachers essay.com.

[4] Labarrete, R. (2021). Assessment for learning in the alternative learning system- education and skills training (ALS-EST) International Journal of Education Humanities and Social Science ISSN: 2582-0745 Vol. 4, No. 01; 2021.

[5] Labarrete, R. (2021). Facilitating instruction in the alternative learning system (ALS). International Journal of Education Humanities and Social Science ISSN: 2582-0745 Vol. 4, No. 01; 2021.

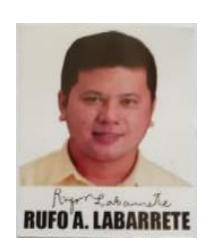

Dr. Rufo A. Labarrete is an Assistant Professor of the College of Education of the Leyte Normal University in Tacloban City, Leyte, the Philippines. He obtained his doctor of Philosophy in Education major in Curriculum and Instruction degree at the University of San Carlos in Cebu City. His research inclination is into the Alternative Learning System. He has attended numerous seminars and training in various and presented research papers in his country and abroad including in Japan. He has also published a number of research articles in international refereed journals. 